\title{
Keys to Effective Listening and Presenting: An Action Plan
}

\author{
T. D. Weerasinghe ${ }^{1}$ and T. J. R. Thisera ${ }^{2}$ \\ ${ }^{1,2}$ Department of Human Resource Management, University of Kelaniya, Sri Lanka \\ ${ }^{1}$ tdtmdananjaya@gmail.com, ${ }^{2}$ jeewanthithisera@gmail.com
}

\begin{abstract}
This is a review article on keys to effective listening and presenting skills which have been identified as two main skills to be improved for effective communication. Accordingly, the article focusses first on listening skills; importance, barriers for effective listening, and keys to improve listening skills. It then moves towards presenting skills while discussing key guidelines to improve verbal, non-verbal and para-verbal aspects of an effective presentation. Finally, this paper proposes an action plan for three months in order to improve these skills in a pragmatic way.
\end{abstract}

Keyword: Listening, Presenting, Soft Skills, Action Plan

\section{Introduction}

Managers, as a part of their jobs, frequently engage in various ways of oral and written communication. Previous researches indicate that more than $90 \%$ of managers' time is allocated for communication activities. Communication should be effective enough to achieve its intended results. Communication is said to be effective when it is received by the correct recipient and understood and acted upon in the manner expected by the sender. If sender is capable enough to get the expected response from the receiver, communication is effective.

Being a good listener and an effective presenter are two key skills that a contemporary manager must sharpen. Once Mahathma Ghandi (n.d) wrote:

"...without listening you have nothing to talk; also without reading you have nothing to write..."

Hence, listening and presentation skills are considered to be two critical skills among communication skills. Accordingly, this article discusses effective 
listening and presentation skills as key skills that every manager should improve.

\section{Effective Listening Skills}

Commination starts with listening. As Mahathma Ghandi said, "without listening there is nothing to talk". This shows that without proper listening skills it is difficult to communicate with others without proper listening skills. Therefore, how one can improve this remarkable skill of listening is addressed in this section. Listening can be identified as a process of receiving, constructing earnings from the message and responding appropriately; may be verbally or non-verbally. Listening is a hard work. Effective listening can be identified as more than just a skill. It is also a matter of attitude. Hence, it is essential to listen others rather speaking in order to be an effective listener. Once a famous psychologist Cari Rogers (n.d) wrote:

\section{"Nothing feels as good as being understood, not evaluated or judged. What I try to share some feeling aspect of myself and my communication is met with evaluation, reassurance, distorting of my meaning, I know what is to be alone"}

The ability to listen effectively does not only mean using the ears. It is not about merely using ears. It is a skill that involves a great deal of concentration, understanding the language and eye contact. Listening skill requires a great deal of practice. It is not a one-short effort. Practicing effective listening skill is a gradual process. But it is a different process for different people. There are lots of ways and means identified and stated by different authors and researchers. Kratz and Kratz (2005) stated the following tips to practice that identical skill of effective listening.

i. Ask questions

ii. Write it down

iii. Focus of the body language of the speaker

iv. Try to keep an open mind when listening

v. Avoid the temptation to interrupt

vi. Seek clarity when appropriate

vii. Try to understand the communicator's body language

viii. Understand the feelings of the communicator

ix. Listen to the tone of voice of the speaker 
When developing effective listening skills understanding once body language is very critical. Importantly paying attention to other people's body language can help to understand others more effectively. By understanding other's body language one can get a clear idea about communicator's genuineness, confidence and interest in what he / she is saying. Immediate areas to concentrate upon are eye contact, expression, handshake and postures (Mandel, 1987). Hence, listening involves a greater degree of concentration on body language of the speaker.

When effectively listening to others, it is important to listen not only to words, but also the tone, the silence and non-verbal and para-verbal part of the communication. Once a great inspirational writer Robin Sharma wrote:

"...when you are effectively listening to another person, it will be the starting point for a deep and genuine human relation..."

Thus, it is concluded that effective listening is a soft skill, most probably categorized under human relation skills which all levels of managers need for effective management. As mentioned by Lesikar et al. (2009) has stated that people should not listen only to words, but also to the silence of a person. Silence does not mean the mere silence. There is a very big message in silence in communication. In a two way communication, silence could mean or imply one or more of the followings. Therefore, silence becomes an important message and need to practice how to listen to silence and understand.

i. Either party is uncomfortable

ii. One or both parties are being polite

iii. One party is taking time to think

iv. Politeness of the speaker or the presenter

v. One or both parties do not know what to say or do next

\subsection{Barriers for effective listening}

There are many barriers for effective listening. Before getting into methods of improving effective listening skills, it is important to identify barriers for effective listening. Different authors and researchers have identified different sets of barriers. Following section reflects the prominent and common barriers as mentioned by Diane (1988). 
Daydreaming is the first barrier for effective listening. Many people daydream when they are supposed to be listening. Instead of focusing on the speaker and attempting to learn something or even mentally composing a response to what is being said many those who have not practices to listen effectively may daydreaming. Daydreaming closes down the possibility of retaining information.

Diane (1988) has identified making mental arguments with the speaker while listening as another barrier for effective listening. Instead of listening to what someone is saying, a poor listener will disagree mentally and think about a rebuttal. People will actually play out a complete argument in their own mind at the same time they should be paying attention to what the other person is really trying to say. This kind of mental arguing is very damaging to the communication process and will often lead to misunderstanding and conflicts between people. The effective listener will wait until the speaker is totally finished with the statement before making a judgment.

As the most common barrier to effective listening, disturbing the conversation before the other person finishes has been identified. This includes talking loudly to others in the audience. Listening power is greater than speaking power. Once Mahathma Ghandi mentioned:

"Indeed, you need strength to talk in-front of an audience, but you need more strength to listen to somebody else when he or she is talking"

Lack of interest is another barrier for why people are not listening to others. How does the saying go? Deal with it. Lack of interest in the speaker's topic, language, body language or examples used does create a difficult situation. Effective listeners try to find useful information in any presentation or talk. A listener with a negative attitude about the message or the speaker will have a tough time being effective as a listener. A good way to increase listening effectiveness is to maintain a positive attitude about the speaker and really work at listening for useful information.

Negative reactions to the speaker's appearance or the delivery method is another barrier for effective listening. Some listeners are quick to find fault with the speaker's dress, voice, or gestures. This tendency of hasty judgments 
makes it difficult to concentrate on the message what the speaker is trying to deliver. This happens frequently with radio personalities. Often, a speaker's looks are totally different from that implied by the sound of the voice. The old proverb saying "you can't judge a book by its cover," is applied here. Because someone appears odd, different, or doesn't match with the mental image you had invented up, doesn't mean that the message will be ineffective or unrewarding. Keep an open mind when listening to people. Finally you may be surprised at what you have learnt from the speaker. Hence, to get the best out of the speaker's talk one must listen effectively and need to avoid making swift judgments.

\subsection{Methods to improve your listening skills}

Having understood that effective listening requires a greater degree of practice different authors have suggested different ways and means to practice this twin skill of listening. The core idea of all the strategies of improving listening skills is that it requires commitment and effort (Mandel, 1987).

As the first key point in improving listening skill, it is suggested to stop talking since people cannot talk and listen at the same time. It does not work properly. Thus, to be an effective listener it needs to switch off talking and switch on listening. Bradbury (2000) stated that this should be practices as a conscious effort.

Second key point is to identify with the speaker. This means putting yourself in the speaker's place. Try to really understand the speaker's view point. What is the motivation behind the message? How do his or her views match up with yours? What is the speaker's agenda? Answering to those questions automatically improve the listening effectiveness through serious concentration.

Asking questions when necessary is another key point of improving effective listening. When you ask questions, two good things happen: first, it fuels your own interest level. If you are in the presence of a good speaker, meaningful questions should bring you some significant added information. Second, your questions may encourage the speaker to expand on the topic of the speech. In communication, questioning also a significant skill which needs a higher 
degree of practice. When questioning the golden rule says better have an open mindset and keep a tradeoff among open ended and close ended questions.

The next key to improve effective listening is the practice of concentration. Focusing on the speaker and the message being delivered should be concentrated. Being able to concentrate is definitely a skill which we all need in today's information rich world. Showing the speaker that you want to listen genuinely is very important key to be developed. Look and act interested in the speaker's comments and listen to understand the message. Reserve your arguments until it's your turn to speak. With this approach, most speakers actually communicate directly with the listener as they present their message. This will make the listening experience much more meaningful the listener. Uncontrolled emotions and temper can cause misunderstanding when you are trying to listen. If you allow your feelings to interfere with your rationality, your listening skills will drop and your comprehension will be deteriorated. Also, it is unlikely that you will retain the attention of the speaker. Thus, as a key it could be recommended that to control emotions and temper when listening to someone else.

Another key practice is the elimination of distractions. Avoid fidgeting with pens, notebooks, or other stuffs. It is difficult to concentrate on a presentation when there are distractions from others in the audience. Typically, etiquette dictates that people should not enter or leave the audience after the speaker has started speaking. But this practice may vary according to the location and the situation.

Avoid jumping to conclusions and making hasty judgments is another key in improving effective listening skills. If you are using your mind and attentionspan to formulate conclusions before the speaker is finished, you may not hear the complete message. You may end up making incorrect conclusions and leave with the wrong message. This is a trap that catches many listeners. If you do so you may miss the best part of the whole talk. Hence, never evaluate someone's message without hearing it completely (Diane, 1988).

When listening to someone else try to carefully and effectively look for the areas of arguments. Listening for areas of agreement will make the speaker's message more meaningful for you and will also make the speaker more comfortable. But while looking for the areas of argument try to catch the main 
point in the talk. That concentration will helpful to improve effective listening. Speaker may provide many details in the talk. Listener must try to concentrate on the main points being made. This will help the listener to develop a clear understanding of what the real message is. Taking notes could help the listener to concentrate on main points. It is not necessary and even practical to record every word, but just get the main ideas. Howard Hendricks once wrote:

"The principle of effective listening, someone has said, is develop a big ear rather than a big mouth"

\section{Effective presentation skills}

Having understood that listening is a very twin skills in communication secondly will get onto another critical skill; effective presentation skills. Delivering a presentation could be difficult, exiting, energy-draining, interesting or all four together. The single most important thing that one has to do to be an effective presenter is to be prepared.

\subsection{Planning the presentation}

Planning is an essential skill in delivering presentations. Without an effective plan presentation will not success. Key considerations when planning a presentation includes;

i. Set the presentation objectives

ii. Understanding the audience

iii. Consider the content of the presentation

Next the presenter needs to establish objectives for the presentation. Effective presentation objectives should be clear, simple, brief, practical and they should facilitate the presenter to get the desired response from the audience. One general objective for all the presentations is to ensure the audience learns something, not sleeps well throughout the presentation. What is the use of setting presentation objectives? Well-developed presentation objectives could be useful to:

i. To plan and deliver the presentation

ii. To eliminate irrelevant parts from the presentation

iii. For good time management in delivering the presentation 
iv. To handle questions effectively

v. To ensure that the required learning has occurred

Once objective setting has finished next is the analysis of the audience. Understanding the audience and visualize it before presenting thing is a key skill. Indeed, the way in which the presentation is prepared and delivered vary depending on the factor; audience. It is essential to get the full awareness about the audience on the following aspects.

i. The size of the audience

ii. Knowledge level of the audience

iii. Language efficacy of the audience

iv. Culture and the interests of the audience

Having understood the nature of the audience, then presenter should consider the most effective way to approach to the audience. There are different methods of approaching the audience: asking a question at the very beginning, showing a video clip, playing music, enclosing the final point or the result first and so forth. The approach must be impressive enough to attract the audience and make the presentation more interesting as it could create a very strong first impression and confidence in the audience (Kratz \& Kratz, 2005).

\subsection{Structure of the presentation}

The next key for effective presenting is deciding the structure of the presentation in advance. The Presentation is to be presented in a clear and logical format. It will help the presenter and audience to understand the message in the presentation effectively. Normally an effective presentation includes three basic components as:

i. The opening

ii. The main body

iii. The conclusion

\subsubsection{The opening}

Start of the presentation must be impressive enough to attract the audience towards the presenter. Following key points must be taken into account at the start of the presentation. 
i. Welcome the audience

ii. Be clear about the purpose of the presentation

iii. Give an outline for the presentation at the beginning

iv. Indicate how long the presentation will take

v. Keep the opening part short and focused on the theme or topic

\subsubsection{The main body}

This is the main part of the presentation which an audience will hear. It will be the main strength of any presentation and for immediate consideration is how a presenter will make the body in a manner to understand easily to the audience. Better to divide the main body into logical sub sections to make the presentation more understandable. All the facts and figures with ground reasons and assumptions are demonstrated in the main body.

\subsubsection{The conclusion}

In the conclusion part the presenter may summarize what has gone before, ask the audience if they have any questions, and pay the gratitude to the audience for their time and given contribution. Conclusion part is the final opportunity for the presenter to reinforce the key elements of the message that have been contained in the presentation.

\subsection{Handling questions}

As mentioned by Bradbury (2000) there are two basic options of how to handle questions. First option is the presenter can take questions throughout the presentation. Second option is questions will take at the end of the presentation. Irrespective of the way you handle questions it is advisable to avoid question time becoming one to one debate with a single member of the audience in an effective presentation.

\subsection{Managing visual aids in an effective presentation}

In today's technologically rich environment we should know how to handle the technology in the presentation. Basically it is about using and managing visual aids in a presentation. Visual aid is an important part of any presentation. It can reinforce the message to be given throughout the presentation. Visual aid reinforces in the audience mind about the idea and 
concept being presented. It will save the time, stimulate interest and effectively add variety to the presentation. There are several techniques that a presenter could use as visual aids in a presentation. Among them Overhead projectors, flip charts, multimedia projectors, posters, banners and black / white boards are very widely used visual aids. Whatever the visual aid used in the presentation the golden rule says presenter should not limited to the particular aid when delivering the presentation. For an instance, when the presenter uses the power point slides he or she may tend to limit to the points mentioned on slides only. It deteriorates the effectiveness of the presentation. Better to use the slide as a tool, not as the entire presentation delivered.

\subsection{Key guidelines for effective presentation skills}

These are considered as key platform skills to improve once presentation skills. In simple words, this is what you must do, physically and verbally when you are leading a presentation in front of an audience (Mandel, 1987).

i. If you are being introduced by someone else to the audience, look at that person when you are introduced.

ii. Walking around while delivering a presentation is better that standing in one place throughout the presentation. It helps the participants' focuses on your words, gestures and postures.

iii. Be able to stand, comfortably balanced, when speaking and listening to participants and/or while using any visual media.

iv. Do not turn back to the participants. Face them as a group when speaking and face an individual when asking or answering questions.

v. Every presenter has his or her own style. Thus, do not copy someone else's for a business presentation $s$ it is not ethical. But it is possible to copy only certain things, such as a certain approach to the topic, effective way of delivering and useful phrases and so forth.

vi. When telling a story to get a point across, the best stories to tell come from your own experience. So, be genuine in presenting something, People will feel your genuineness. At the end the importance thing is not how the audience hears or what they hear and see, but how they feel. Thus, genuine communication in presentations may increase the effectiveness of it. 
vii. Use humor. It is most effective when it is appropriate; not offensive or insulting to participants. Many presenters use humor; probably most presenters use at least a little bit of it. Humor is most effective when it is used occasionally; a presentation that is injected with humor rather than being immersed in it.

\subsection{Tips on using the voice effectively in a presentation}

i. Vary the volume of your voice

Be loud enough to hear, yet still emphasizing key points with a bit more volume or a bit less volume.

Your speaking voice should not seem like shouting, though it will have to louder than a one-on-one conversation.

ii. Vary your talking speed accordingly

Normal speech is about 125 words per minute; the audience will know you are emphasizing a particular point if you slow down when saying it.

iii. Use silence and pauses to direct or re-direct participants' attention to something

A pause of 5 or 6 seconds after asking the audience a question is the non-verbal signal to them that it is their turn to talk; that you expect them to respond.

\subsection{Nonverbal element in an effective presentation}

Frequently an audience is more stimulated not only by verbal aspect of the presentation, but also due to the para-verbal and nonverbal aspects of it. Thus, when delivering a presentation it is advisable to consider eye contact and gestures as critical to improve the effectiveness of the presentation (Kratz \& Ktatz, 2005).

\section{- Maintaining eye contact}

Eye contact for two seconds with different participants in the audience is appropriate. But not too strong eye contact with one person for a longer period of time. Longer eye contact is suitable when answering a question. Eye contact tells people you are listening and suggests that they listen to you. 


\section{- Gestures}

The main thing is to be your natural self. Avoid clutching the podium or other behaviors that draw attention away from the message:

- Jingling change or keys in your pocket

- Playing with a marker, a pen, laser light, or some other object in your hands.

- Nervous fidgeting, rocking back-and-forth from heel to toe, excessive tension in shoulders and arms, poor posture, and etc.

When pointing to someone or something, use your "whole hand" instead of pointing out using one finger.

\section{Action plan for improving listening and presentation skills}

Having understood that listening and presenting is two twin skills in communication, here the author presents an action plan for three months which is useful to be followed by anybody; especially managers those who need to be mastered in these two critical skills.

Table 01: Action plan to improve listening skills and presenting skills

\begin{tabular}{|l|l|l|}
\hline Time Frame & \multicolumn{1}{|c|}{$\begin{array}{c}\text { To improve listening } \\
\text { skills }\end{array}$} & $\begin{array}{c}\text { To improve presenting } \\
\text { skills }\end{array}$ \\
\hline First Month & $\begin{array}{l}\text { i. } \begin{array}{l}\text { Identify the weak } \\
\text { points of my listening } \\
\text { habits by artificially } \\
\text { engaging in small } \\
\text { conversations with } \\
\text { friends having one as } \\
\text { an observer. }\end{array} \\
\text { ii. } \begin{array}{l}\text { Further ask several } \\
\text { people at several } \\
\text { occasions such as the } \\
\text { work place and when I } \\
\text { am with friends to } \\
\text { point out weaknesses } \\
\text { that I want to improve. }\end{array}\end{array}$ & $\begin{array}{l}\text { i. Firstly start the } \\
\text { practice by listening } \\
\text { to family members } \\
\text { and peers in the } \\
\text { workplace }\end{array}$ \\
& $\begin{array}{l}\text { iisten for the best } \\
\text { speakers, speeches } \\
\text { and watch their } \\
\text { gestures, postures, } \\
\text { tone, and intonation } \\
\text { when they are doing } \\
\text { their speeches. }\end{array}$ \\
& iii. $\begin{array}{l}\text { Refer to the ways of } \\
\text { improving } \\
\text { presentation skills and }\end{array}$ \\
\hline
\end{tabular}


Kelaniya Journal of Human Resource Management

Volume 09-Number 01-January 2014 \& Number 02-July 2014

\begin{tabular}{|c|c|c|}
\hline Time Frame & $\begin{array}{c}\text { To improve listening } \\
\text { skills }\end{array}$ & $\begin{array}{c}\text { To improve presenting } \\
\text { skills }\end{array}$ \\
\hline & $\begin{array}{l}\text { iii. List down those } \\
\text { weaknesses to which I } \\
\text { have to pay more } \\
\text { attention. } \\
\text { iv. } \\
\text { Refer to means of } \\
\text { improving listening } \\
\text { skills by watching } \\
\text { videos and referring } \\
\text { books. }\end{array}$ & \begin{tabular}{|l} 
preparation of \\
presentation skills. \\
iv. \\
Identify my \\
weaknesses when \\
compared to those \\
presenters. \\
v. Find the ways to \\
improve those \\
weaknesses.
\end{tabular} \\
\hline Second Month & $\begin{array}{l}\text { i. Watch videos of } \\
\text { speakers and } \\
\text { summarize it to ensure } \\
\text { that I focused on twin } \\
\text { points. } \\
\text { ii. Do the listening } \\
\text { activities available } \\
\text { online. (E.g.: first } \\
\text { listen for a particular } \\
\text { conversation and then } \\
\text { answer questions - Eg: } \\
\text { IELTS) } \\
\text { iii. Do a progress review } \\
\text { in comparison to the } \\
\text { first month. }\end{array}$ & $\begin{array}{l}\text { i. Select a specific topic } \\
\text { and assume the } \\
\text { audience to which I } \\
\text { have to do the } \\
\text { presentation. } \\
\text { ii. Do researches, } \\
\text { prepare notes, and use } \\
\text { any necessary } \\
\text { handouts to give the } \\
\text { important message to } \\
\text { the audience. } \\
\text { iii. Avoid negative } \\
\text { thoughts about } \\
\text { presentations }\end{array}$ \\
\hline Third Month & $\begin{array}{l}\text { i. When it is a } \\
\text { conversation I will stop } \\
\text { talking much giving } \\
\text { chance to the speaker } \\
\text { knowing that I can gain } \\
\text { more benefits through } \\
\text { listening. }\end{array}$ & $\begin{aligned} & \text { i. } \text { Be prepared well } \\
& \text { ii. } \text { Have a strong } \\
& \text { beginning } \\
& \text { iii. } \text { Rehearse the } \\
& \text { presentation } \\
& \text { permitting the time } \\
& \text { limits }\end{aligned}$ \\
\hline
\end{tabular}


Kelaniya Journal of Human Resource Management

Volume 09-Number 01-January 2014 \& Number 02-July 2014

\begin{tabular}{|c|c|c|}
\hline Time Frame & $\begin{array}{c}\text { To improve listening } \\
\text { skills }\end{array}$ & $\begin{array}{c}\text { To improve presenting } \\
\text { skills }\end{array}$ \\
\hline & \begin{tabular}{|l} 
ii. I will concern about \\
my surrounding and \\
when I engaged in such \\
activities I will start it \\
by thinking that always \\
I can gain something \\
by listening. \\
iii. Try to have an open \\
mind \\
iv. Try to focus on main \\
points. \\
v. Summarize things to \\
ensure I got all the \\
stuff effectively. \\
vi. Do a review
\end{tabular} & $\begin{aligned} & \text { iv. } \text { Choose the } \\
& \text { presentation tools } \\
& \text { carefully. } \\
& \text { v. } \\
& \text { Check for the timing, } \\
& \text { intonation using MS } \\
& \text { PowerPoint "records } \\
& \text { your narrations" } \\
& \text { option. } \\
& \text { vi. Rehearse in front of } \\
& \text { the mirror to be aware } \\
& \text { on my gestures and } \\
& \text { postures. } \\
& \text { vii. } \\
& \text { Monitor results at the } \\
& \text { end of third month }\end{aligned}$ \\
\hline
\end{tabular}

Source: Authors

\section{Conclusion}

Communication is an eternal activity that everybody has to engage in from birth to death within once span of life. Especially managers, as a part of their jobs frequently engage in various ways of oral and written communication. Being an active listener and an effective presenter are two skills a modern manager must sharpen to effectively communicate with others. The first part of this paper has described the meaning of effective listening, features of an effective listener, barriers for effective listening and methods to improve effective listening skills respectively. It is recognized that the most common barriers for effective listening are daydreaming when listening, making mental arguments with the speaker, jumping into a conversation before the other person has finished, and lack of interest. Without listening, there is nothing to talk. Thus, the first key point has recognized in improving listening skill is stopping talking when turn to listen. This paper concludes that a great degree of practice and concentration is required to improve the effective listening skills. 
It then explained another twin in communication skills; effective presentation skills. The most thing is recognized as the preparation before the presentation. Setting presentation objectives, understanding the audience, effective use of visual aids and handling questions from the audience effectively has explained as key success point in the paper respectively. Furthermore, the paper described key guidelines to improve verbal, non-verbal and para-verbal aspects of an effective presentation. Finally, it is suggested an action plan for three months to improve these two salient skills; effective listening and presenting.

\section{References}

Bradbury, A. (2000). Successful Presentation Skills. Kogan Page.

Diane, B. (1988). The Business of Listening. Crisp Publications.

Kratz, D. \& Kratz, A. (2005). Effective Listening Skills. New York: McGraw-Hill Publishing.

Lesikar, R., Flatley, M., Rentz, K. and Pande, N. (2009). Business Communication (11th Ed). New Delhi: McGraw - Hill Education.

Mandel, S. (1987). Effective Presentation Skills. Crisp Publication.

\section{Bibliography}

Andrews, P. H. \& Herschel, A. (1997), Organizational Communication, New York: Houghton Mifflin.

Giblin, L. (2001). The art of dealing with people. Kindle Edition.

Guffey, M. E. (2001), Essentials of Business Communication, $5^{\text {th }}$ ed., New York: South Western College publishing.

Harvard Business School Publishing, (2005), Business Etiquette for New Workplace, Harvard Business Review Press, USA.

Lesikar R. V., Flatley M. E., Rentz K., and Pande N., (2013), Business Communication: Making Connections in a Digital World, $11^{\text {th }} \mathrm{Ed}$., McGraw-Hill Education (India) Pvt. Ltd, New Delhi. 
Kelaniya Journal of Human Resource Management Volume 09-Number 01-January 2014 \& Number 02-July 2014

McGinnis, A. (1985). Bringing out the best in people. Augsbary Books.

Ober. S. (2000), Contemporary Business Communication, New York: Houghton Mifflin.

Opatha, H. H.D.N.P. (2012), Human Resource Management: Personnel. Department of HRM, Faculty of Management studies and Commerce, University of Sri Jayewardenepura.

Opatha, H.H.D.N.P., Personal Quality, Department of Human Resource Management, University of Sri Jayewardenepura, Nugegoda, Sri Lanka.

Sabath, A.M., (2013), Business Etiquette in Brief: The Competitive Edge for Todays Professional, Adams Media, New York.

Weerasinghe, T. D. (2014, Jun). The Nexus Between Corporate Team Management and the Buddhist Perspective: A Review. Indian Journal of Research in Management, Business and Social Sciences, 02(02), 59 - 63. 